\title{
Association between in vitro fertilization success rate and ambient air pollution: a possible explanation of within-year variation of in vitro fertilization success rate
}

\author{
Jongkyeong Kang, MS', Ji Yi Lee, PhD², Haengseok Song, PhD³ , Seung Jun Shin, $\mathrm{PhD}^{1}$, Jayeon Kim, MD, MPH \\ ${ }^{1}$ Department of Statistics, Korea University, Seoul; ${ }^{2}$ Department of Environmental Science and Engineering, Ewha Womans University, Seoul; \\ ${ }^{3}$ Department of Biomedical Science, CHA University, Seongnam; ${ }^{4}$ CHA Fertility Center, Seoul Station, CHA University, Seoul, Korea
}

\section{Objective}

To evaluate patterns in air pollution concentrations and in vitro fertilization (IVF) success rates using data from a large, long-term clinical database.

\section{Methods}

We conducted a retrospective cohort study investigating South Korean women who pursued IVF and embryo transfer (IVF-ET) between 2011 and 2017. Hourly concentrations of air pollutants measured at 318 air quality monitoring sites in South Korea between 2011 and 2017 were obtained from the National Institute of Environmental Research. Monthly trends in pregnancy rates and concentrations of air pollutants were assessed.

\section{Results}

A total of 34,427 IVF-ET cycles in 18,478 patients were analyzed. The mean age of women at the time of IVF-ET was 36.6 years. The clinical pregnancy rate in the IVF-ET cycle was $30 \%$. Analysis of pregnancy failure rates by month showed that IVF-ET failure rates tended to be higher in March and April and lower in July and August. Concentrations of air pollutants including particulate matter (PM) less than $10 \mu \mathrm{m}$ in diameter, PM less than $2.5 \mu \mathrm{m}$ in diameter, sulfur dioxide, nitrogen dioxide, and carbon monoxide were highest in March and April and lowest between July and September.

\section{Conclusion}

Within-year variations were similar between IVF-ET failure rates and air pollution concentrations based on analysis of a large, long-term database. Specifically, IVF-ET success rates were highest when PM concentrations were lowest. Further studies are warranted to examine the mechanisms accounting for the association between IVF success and air pollutant exposure.

Keywords: Air pollution; In vitro fertilization; Pregnancy rate; Particulate matter

\section{Introduction}

For decades, there has been growing awareness that ambient air pollution compromises human health. Particulate matter (PM) and ground-level ozone $\left(\mathrm{O}_{3}\right)$ are the most problematic pollutants in terms of harm to human health, followed by benzopyrene (an indicator for polycyclic aromatic hydrocarbons [PAHs]) and nitrogen dioxide $\left(\mathrm{NO}_{2}\right)$ [1]. Of particular concern is airborne PM less than $2.5 \mu \mathrm{m}$ in diameter $\left(\mathrm{PM}_{2.5}\right)$, which has a higher surface area to mass ratio than

Received: 2019.04.24. Revised: 2019.08.23. Accepted: 2019.08.27.

Corresponding author: Seung Jun Shin, $\mathrm{PhD}$

Department of Statistics, Korea University, 145 Anam-ro,

Seongbuk-gu, Seoul 02841, Korea

E-mail: sjshin@korea.ac.kr

https://orcid.org/0000-0001-8119-3200

Jayeon Kim, MD, MPH

CHA Fertility Center, Seoul Station, CHA University, 416 Hangang-daero, Jung-gu, Seoul 04637, Korea

E-mail: jayeon_kim@chamc.co.kr

https://orcid.org/0000-0003-3828-6086

Articles published in Obstet Gynecol Sci are open-access, distributed under the terms of the Creative Commons Attribution Non-Commercial License (http://creativecommons. org/licenses/by-nc/3.0/) which permits unrestricted non-commercial use, distribution, and reproduction in any medium, provided the original work is properly cited.

Copyright $\odot 2020$ Korean Society of Obstetrics and Gynecology 


\section{Obstetrics \& Gynecology Science}

Jongkyeong Kang, et al. Pattern of air pollution and IVF result

PM less than $10 \mu \mathrm{m}$ in diameter $\left(\mathrm{PM}_{10}\right)$ and can directly reach the lung alveoli. $\mathrm{PM}_{2.5}$ has been shown to activate multiple pathophysiologic processes, which, in turn, may contribute to various health problems such as cardiovascular disease [2], stroke [3], respiratory diseases [4,5], and infertility [6].

There are several mechanisms by which air pollution may impact human health. Specifically, PAHs and heavy metals (e.g., $\mathrm{Cu}, \mathrm{Pb}$, and $\mathrm{Zn}$ ) contained in PM may affect health by disrupting endocrine activity $[7,8]$. Additionally, PM contains compounds with estrogenic, antiestrogenic, and antiandrogenic activities that can affect gonadal steroidogenesis and gametogenesis [7]. Air pollutants can also induce DNA modification through the formation of DNA adducts, leading to changes in gene expression or the appearance of epigenetic mutations or modifications such as an alteration of DNA methylation $[9,10]$. These mechanisms can affect all health functions, especially reproduction, in which gonadal endocrine function plays a critical role and genetic material is passed down to offspring.

Previous studies have provided evidence that both shortand long-term exposure to particulate air pollution significantly impact female reproductive function. Acute preconception exposure to diesel exhaust particles and chronic exposure to $\mathrm{PM}_{2.5}$ present in ambient air were implicated in the disruption of inner cell mass and trophectoderm lineage segregation at the blastocyst stage $[11,12]$. Defective embryonic development after implantation resulted in increased numbers of implantation failures, decreased numbers of viable fetuses, and higher rates of miscarriage $[13,14]$. Available literature demonstrates poor reproductive outcomes such as preeclampsia and preterm delivery in humans after exposure to traffic pollution and diesel exhaust during pregnancy [6].

Several epidemiologic studies have investigated the association between air pollution and in vitro fertilization (IVF) treatment outcomes; however, these studies included small numbers of patients in limited geographic areas [15-17]. In addition, the largest study only analyzed $\mathrm{PM}_{10}$ as the primary exposure, which has less health impact compared to that of $\mathrm{PM}_{2.5}[17]$.

We performed this study to generate a hypothesis about the possible association between air pollution and IVF treatment outcome. To accomplish this, we evaluated patterns in air pollution concentrations and IVF success rates using a large, and long-term clinical database.

\section{Materials and methods}

\section{Data}

Our study population comprised infertile women who underwent 1 or more fresh IVF and embryo transfer (IVF-ET) cycles at the Fertility Centre CHA Hospital between January 2011 and December 2017. This study included all fresh IVF cycles in women aged 20-44 years performed during the study period. Donor oocyte IVF cycles were excluded from this study. Patients' baseline serum anti-Müllerian hormone (AMH) level, body mass index (BMI), and additional laboratory data were obtained from medical records.

\section{Fresh in vitro fertilization and embryo transfer procedures}

For fresh IVF-ET, controlled ovarian stimulation was initiated with a daily injection of gonadotrophins that was individualized for the woman's age, ovarian reserve, and previous ovarian response to gonadotrophins during stimulation cycles. The dose of gonadotrophin was adjusted after 4 days of stimulation according to each patient's ovarian response, as assessed through ultrasonographic monitoring of follicular growth and serum estradiol levels. Administration of cetrorelix acetate (Cetrotide ${ }^{\circledR}$; Merck-Serono, Seoul, Korea) was started on the day when the lead follicle reached 13-14 mm in diameter and continued until at least 2 follicles reached $18 \mathrm{~mm}$ in diameter, at which point recombinant human chorionic gonadotropin (hCG, Ovidrel@; Merck-Serono) was administered to trigger ovulation. Transvaginal ultrasoundguided oocyte retrieval was performed 35-36 hours after hCG administration. Patients underwent either a cleavage stage or a blastocyst transfer at 3-5 days after oocyte retrieval. The number of embryos transferred was determined based on the embryo quality and the age of the patient, in accordance with the national guideline from the Ministry of Health and Welfare in Korea [18]. Starting on the day of oocyte retrieval, luteal support with daily transvaginal or intramuscular progesterone was provided until either a negative pregnancy test (serum $\beta$-hCG level $<5 \mathrm{mlU} / \mathrm{mL}$ ) or the pregnancy reached 8 weeks of gestation. Clinical pregnancy was defined as the confirmation of a gestational sac in the uterine cavity by transvaginal ultrasound at 5-6 weeks gestation. 


\title{
Obstetrics \& Gynecology Science
}

\author{
Vol. 63 , No. 1, 2020
}

\section{Air pollutant exposure assessment}

Hourly concentrations of $\mathrm{PM}_{10}, \mathrm{NO}_{2}$, sulfur dioxide $\left(\mathrm{SO}_{2}\right)$, carbon monoxide $(\mathrm{CO})$, and $\mathrm{O}_{3}$ measured at 318 air quality monitoring sites in South Korea during 2011-2017 were obtained from the National Institute of Environmental Research. A pilot analysis of the data showed consistent air pollutant concentrations among the monitoring sites. Finally, we calculated the daily average concentrations of the air pollutants across the 318 sites. Raw data for $\mathrm{PM}_{2.5}$, and consequently its daily averages, were missing for nearly $40 \%$ of the time points from 2015 to 2017, whereas raw data for all pollutants other than $\mathrm{PM}_{2.5}$ were missing for less than $5 \%$ of the time points and their daily averages were available for the entire research period (2011-2017).

\section{Statistical analyses}

Unlike the air pollutant concentrations, it was difficult to identify the within-year variations in IVF failure rates from the raw data. Let $Y_{i}(t)$ be an observed value, such as failure rate or $\mathrm{PM}_{10}$ concentration, at $t \in[0, T)$ within the $i^{\text {th }}$ year $(i=1, \cdots, N)$. To uncover within-year variations possibly contained in $Y_{i}(t)$, we assumed a simple additive structure:

$$
Y_{i}(t)=\mu_{i}+\alpha(t)+\varepsilon_{i}(t)
$$

where $\mu_{i}$ was a year-specific effect indexed by $i, \alpha(t)$ denoted the within-year variation, and $\varepsilon_{i}(t)$ was random error from $N\left(0, \sigma^{2}\right)$ at a given $t$. Here, $T$ was a given constant, such as $T=12$ or 365 for monthly or daily reports $Y_{i}(t)$, respectively. Our primary goal was to estimate and compare the within-year variations $\alpha(t)$ for both failure rate and air quality.

To this end, we first estimated the year-specific effect, determined by $\hat{\mu}_{i}=\int_{0}^{T} Y_{i}(t) d t$, and the error variance, determined by $\hat{\sigma}^{2}=\sum_{i=1}^{N} \int_{0}^{T}\left(Y_{i}(t)-\hat{\mu}_{i}\right)^{2} d t / N$. We then computed.

$$
Z_{i}(t)=\frac{Y_{i}(t)-\widehat{\mu}_{i}}{\widehat{\sigma}} .
$$

Notice that $Z_{i}(t)$ was a standardized estimate of $\alpha(t)+\varepsilon_{i}(t)$. Finally, the seasonal variation $\alpha(t)$ was estimated by applying B-spline smoothing to $Z_{i}(t)$ [19].

\section{Results}

We analyzed the outcomes of 34,427 IVF-ET in 18,478 patients by applying machine learning approaches. The machine learning approaches refer to a collection of statistical
Table 1. Characteristics of patients and in vitro fertilization and embryo transfer cycles at a fertility center in Seoul, Korea, during

\begin{tabular}{|c|c|c|}
\hline Characteristics & Values & $P$-value \\
\hline Age (yr) & $36.6 \pm 4.3$ & 0.035 \\
\hline Spring & $36.6 \pm 4.3$ & \\
\hline Summer & $36.5 \pm 4.3$ & \\
\hline Fall & $36.5 \pm 4.3$ & \\
\hline Winter & $36.7 \pm 4.3$ & \\
\hline Body mass index $\left(\mathrm{kg} / \mathrm{m}^{2}\right)$ & $21.41 \pm 3.03$ & 0.615 \\
\hline Spring & $21.45 \pm 3.06$ & \\
\hline Summer & $21.38 \pm 3.02$ & \\
\hline Fall & $21.37 \pm 3.01$ & \\
\hline Winter & $21.43 \pm 3.03$ & \\
\hline Anti-Müllerian hormone (ng/mL) & $2.77 \pm 2.87$ & 0.322 \\
\hline Spring & $2.82 \pm 2.90$ & \\
\hline Summer & $2.77 \pm 2.89$ & \\
\hline Fall & $2.72 \pm 2.79$ & \\
\hline Winter & $2.78 \pm 2.90$ & \\
\hline No. of oocytes retrieved & $9.16 \pm 6.93$ & 0.102 \\
\hline Spring & $9.29 \pm 7.09$ & \\
\hline Summer & $9.03 \pm 6.84$ & \\
\hline Fall & $9.12 \pm 6.87$ & \\
\hline Winter & $9.19 \pm 6.92$ & \\
\hline \multicolumn{3}{|l|}{$\begin{array}{l}\text { Seasonal distribution of oocyte retrieval } \\
\text { or frozen embryo transfer (\%) }\end{array}$} \\
\hline Spring & 26.1 & \\
\hline Summer & 25.7 & \\
\hline Fall & 25.0 & \\
\hline Winter & 23.2 & \\
\hline $\begin{array}{l}\text { Clinical pregnancy }{ }^{\mathrm{a})} \text { rate by season of } \\
\text { oocyte retrieval or frozen embryo } \\
\text { transfer }(\%)\end{array}$ & 29.6 & 0.738 \\
\hline Spring & 29.6 & \\
\hline Summer & 29.9 & \\
\hline Fall & 29.5 & \\
\hline Winter & 29.1 & \\
\hline Distribution of poor responders ${ }^{b)}(\%)$ & & 0.565 \\
\hline Spring & 40.0 & \\
\hline Summer & 39.1 & \\
\hline Fall & 39.4 & \\
\hline Winter & 40.0 & \\
\hline
\end{tabular}
2011-2017 $(n=34,427)$

Values are shown as mean \pm standard deviation or percentages.

${ }^{a} V$ Visualization of gestational sac on trans-vaginal ultrasound between 5th and 6th week of gestation; ${ }^{b}$ Age $\geq 38$ years or anti-Müllerian hormone $\leq 1.0 \mathrm{ng} / \mathrm{mL}$. 


\section{Obstetrics \& Gynecology Science}

Jongkyeong Kang, et al. Pattern of air pollution and IVF result

methods that uncover informative signals in large-scale data without relying on stringent model assumptions. Table 1 summarizes the clinical characteristics of the treatment cycles in the study population. The mean patient age at the time of IVF-ET was 36.6 years. The average BMI was $21.4 \mathrm{~kg} / \mathrm{m}^{2}$ and

Table 2. Concentrations of air pollutants by season at a fertility center in South Korea during 2011-2017

\begin{tabular}{|c|c|c|}
\hline Characteristics & Concentration & $P$-value \\
\hline $\mathrm{PM}_{10}\left(\mu \mathrm{g} / \mathrm{m}^{3}\right)$ & $47.8065 \pm 11.7959$ & $<0.001$ \\
\hline Spring & $59.7015 \pm 6.6690$ & \\
\hline Summer & $37.2329 \pm 6.4223$ & \\
\hline Fall & $40.1755 \pm 6.4689$ & \\
\hline Winter & $53.6688 \pm 9.0348$ & \\
\hline $\mathrm{PM}_{2.5}\left(\mu \mathrm{g} / \mathrm{m}^{3}\right)$ & $25.7007 \pm 5.1526$ & 0.003 \\
\hline Spring & $28.8735 \pm 3.8556$ & \\
\hline Summer & $21.1215 \pm 4.1021$ & \\
\hline Fall & $23.0524 \pm 4.3771$ & \\
\hline Winter & $29.6003 \pm 2.1043$ & \\
\hline $\mathrm{NO}_{2}(\mathrm{ppm})$ & $0.0241 \pm 0.0045$ & $<0.001$ \\
\hline Spring & $0.0255 \pm 0.0020$ & \\
\hline Summer & $0.0183 \pm 0.0021$ & \\
\hline Fall & $0.0242 \pm 0.0034$ & \\
\hline Winter & $0.0286 \pm 0.0025$ & \\
\hline $\mathrm{SO}_{2}(\mathrm{ppm})$ & $0.0050 \pm 0.0010$ & $<0.001$ \\
\hline Spring & $0.0053 \pm 0.0004$ & \\
\hline Summer & $0.0043 \pm 0.0004$ & \\
\hline Fall & $0.0042 \pm 0.0005$ & \\
\hline Winter & $0.0061 \pm 0.0009$ & \\
\hline CO (ppm) & $0.5142 \pm 0.1057$ & $<0.001$ \\
\hline Spring & $0.4978 \pm 0.0406$ & \\
\hline Summer & $0.4077 \pm 0.0188$ & \\
\hline Fall & $0.4952 \pm 0.0692$ & \\
\hline Winter & $0.6613 \pm 0.0668$ & \\
\hline $\mathrm{O}_{3}(\mathrm{ppm})$ & $0.0264 \pm 0.0083$ & $<0.001$ \\
\hline Spring & $0.0362 \pm 0.0052$ & \\
\hline Summer & $0.0304 \pm 0.0061$ & \\
\hline Fall & $0.0219 \pm 0.0045$ & \\
\hline Winter & $0.0179 \pm 0.0033$ & \\
\hline
\end{tabular}

Data are shown as mean \pm standard deviation.

$\mathrm{PM}_{10}$, particulate matter less than $10 \mu \mathrm{m}$ in diameter; $\mathrm{PM}_{2.5}$, particulate matter less than $2.5 \mu \mathrm{m}$ in diameter; $\mathrm{NO}_{2}$, nitrogen dioxide; $\mathrm{SO}_{2}$, sulfur dioxide; $\mathrm{CO}$, carbon monoxide; $\mathrm{O}_{3}$, ground-level ozone; ppm, parts per million. the mean serum AMH level was $3.0 \mathrm{ng} / \mathrm{mL}$. An average of 9 oocytes was retrieved. The clinical pregnancy rate (CPR) per transfer was $29.6 \%(10,177 / 34,427$ cycles). There were no significant seasonal differences in the patients' basal characteristics, AMH level, number of ET cases, CPR, and the percentage of poor responders (age $\geq 38$ years or serum $\mathrm{AMH}$ $\leq 1.0 \mathrm{ng} / \mathrm{mL}$ ).

The average daily concentrations of $\mathrm{PM}_{10}, \mathrm{PM}_{2.5}, \mathrm{NO}_{2}, \mathrm{SO}_{2}$, $\mathrm{CO}$, and $\mathrm{O}_{3}$ were $47.8 \mu \mathrm{g} / \mathrm{m}^{3}, 25.2 \mu \mathrm{g} / \mathrm{m}^{3}, 0.024$ parts per million (ppm), 0.005 ppm, 0.514 ppm, and 0.026 ppm, respectively (Table 2). All pollutants exhibited distinct seasonal variations (Fig. 1A). The concentrations of most pollutants were lowest in summer and highest in winter, except for that of $\mathrm{O}_{3}$, which was lowest in fall and highest in spring. The IVF treatment failure rates had no distinct within-year variations during the 7-year study period (Fig. 1B).

To investigate the possible association between CPR and air pollutant concentrations, we compared the within-year variation in CPR to that of the 5 different air pollutants, which had nearly identical seasonal patterns. The CPRs of total IVF
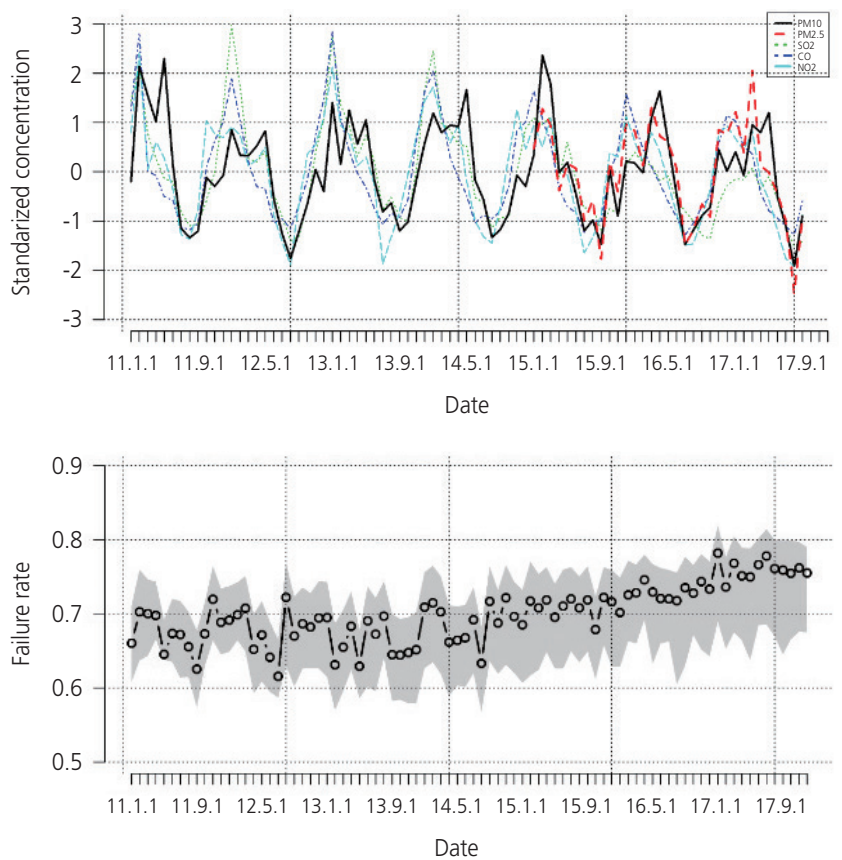

Fig. 1. Within-year variations in air pollutant concentrations $(A)$ and in vitro fertilization treatment failure rates (B) throughout the study period (January 2011-December 2017). PM $_{10}$, particulate matter less than $10 \mu \mathrm{m}$ in diameter; $\mathrm{PM}_{2.5}$, particulate matter less than $2.5 \mu \mathrm{m}$ in diameter; $\mathrm{SO}_{2}$, sulfur dioxide; $\mathrm{CO}$, carbon monoxide; $\mathrm{NO}_{2}$, nitrogen dioxide. 


\title{
Obstetrics \& Gynecology Science
}

\author{
Vol. 63, No. 1, 2020
}

treatment cycles were highest in July and August and lowest in February and March (Fig. 2); this pattern was the exact opposite of the air pollutant pattern. Assessment of the correlations between within-year variations in CPR and air pollutants revealed significant correlations between the within-year variations of CPR for IVF-ET cycles and the concentrations of $\mathrm{NO}_{2}, \mathrm{PM}_{10}$, and $\mathrm{PM}_{2.5}$ (Table 3).

\section{Discussion}

The present cohort study of 34,427 IVF-ET cycles in South Korea between January 1, 2011, and December 31, 2017, provided compelling evidence that exposure to PM air pollution was associated with decreased pregnancy rates in women undergoing fresh IVF-ET treatments, as there were similar within-year variations between IVF-ET failure rates and air pollution levels. To our knowledge, this is the largest study to report a possible association between air pollution

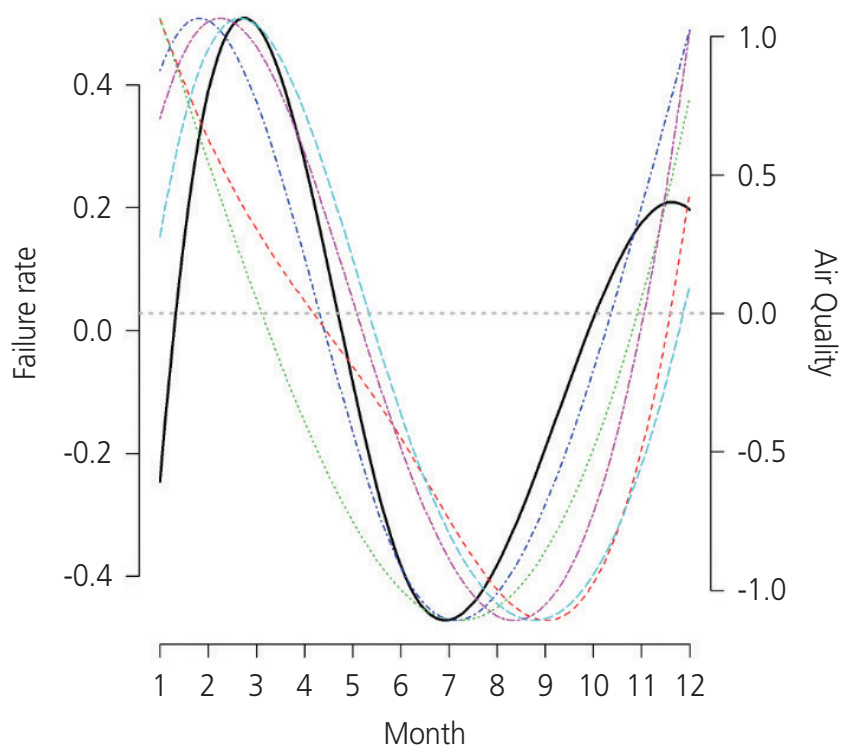

Fig. 2. Comparisons of within-year variations in total in vitro fertilization failure rates and air pollutant concentrations. and IVF outcome. Previous studies have reported positive associations between exposure to $\mathrm{PM}_{2.5}, \mathrm{PM}_{10}$, and suspended particulates and IVF outcomes $[11,12,17,19,20]$. However, most of these studies included small numbers of patients and the exposure periods and sizes of PM investigated were inconsistent among the studies.

In our study, although there was no significant within-year variation in CPR, the CPR of IVF-ET tended to be higher in summer. Previous reports investigating within-year variation in IVF-ET outcomes showed inconsistent results. Wood et al. [21] conducted a 4-year retrospective analysis and reported a significant improvement in IVF outcomes in cycles performed in summer months. Stolwijk et al. [22] reported improved pregnancy rates from November to February. Finally, a recent study failed to demonstrate any significant seasonal influence on IVF outcomes [23]. In previous reports, the possible etiology of seasonal variances in IVF success rates was purported to be the length of day, which might suggest the effects of vitamin $D$ exposure and melatonin on the female reproductive tract [24]. However, no study has assessed the possible role of air pollutants in the withinyear variation of IVF outcomes. In our study, the patterns of within-year variation in IVF outcomes were opposite to those of the PM concentrations, indicating that the CPR of IVF cycles was lower when the air quality was worse. Several confounding factors should be considered in interpreting this possible association between air pollution and IVF outcome. First, the severity of air pollution could have differed among the patients' residences. However, our analyses revealed no significant differences in PM concentrations among regions across the country. Likewise, the IVF treatment outcomes did not differ by region. Second, as mentioned above, there is a possible seasonal effect of day length and vitamin D exposure. Finally, various clinical factors can influence IVF success, including patient age; the cause of infertility; and the quality of the oocyte, sperm, or embryo. Although it is important to adjust for all possible confounding factors to accurately access the association between 2 variables, this retrospective

Table 3. Correlation coefficient between estimated within year variation between in vitro fertilization (IVF) success rate and concentration levels of sulfur dioxide $\left(\mathrm{SO}_{2}\right)$, carbon monoxide $(\mathrm{CO})$, nitrogen dioxide $\left(\mathrm{NO}_{2}\right)$, particulate matter less than $10 \mu \mathrm{m}$ in diameter $\left(\mathrm{PM} \mathrm{M}_{10}\right)$, and particulate matter less than $2.5 \mu \mathrm{m}$ in diameter $\left(\mathrm{PM}_{2.5}\right)$ along with $P$-values in parentheses

\begin{tabular}{cccccc}
\hline & $\mathbf{S O}_{2}$ & $\mathbf{C O}$ & $\mathbf{N O}_{2}$ & $\mathbf{P M}_{10}$ & $\mathbf{P M}_{.2 .5}$ \\
\hline IVF success rate & $0.481(0.114)$ & $0.558(0.059)$ & $0.787(0.002)$ & $0.719(0.008)$ & $0.758(0.004)$ \\
\hline
\end{tabular}




\section{Obstetrics \& Gynecology Science}

Jongkyeong Kang, et al. Pattern of air pollution and IVF result

study compared the overall patterns of the variables based on a large clinical dataset. Additionally, as this is the first study to examine the relationship between within-year variation in IVF outcomes and air pollution, we expect this to be a hypothesis-generating study that provides pilot data for future studies investigating the possible association between air pollution and IVF outcome. It is hard to render a definite conclusion based on our results; however, our findings support the hypothesis that air pollution could be a major factor influencing IVF success rates. Based on the large number of patients included, the long study period, and the wide geographical region included in our study, our results showing concordance between seasonal variation in IVF outcomes and air pollution warrant additional studies.

Most previous studies investigating the association between air pollution and IVF outcomes evaluated the effect of acute, short-term exposure to air pollutants $[12,17,25]$ and reported inconsistent results. Choe et al. [17] reported that exposure to air pollution for 9 to 11 days after ET was associated with a decreased probability of intrauterine pregnancy. Another study reported that exposure to high levels of particulate air pollution during the follicular phase, which usually lasts 2 weeks, was associated with early pregnancy loss in couples pursuing IVF [12]. Moreover, exposure to high $\mathrm{NO}_{2}$ concentrations between ovulation induction initiation and ET was associated with lower live-birth rates [26]. However, the exposure period of air pollutants is yet to be defined with respect to their effects on human fecundability. An animal study reported that intratracheally instilled carbon-14 passed through the air-blood barrier and was present at the highest concentration $(0.1-1.0 \%$ of the instilled carbon-14) in the liver and spleen after 14 days [27]. A recent study using PAH labeled with radioactive iodine showed that PAH was mostly cleared within 48 hours after exposure, with less than 1\% passing through the air-blood barrier or hepatobiliary system and accumulating in other internal organs [28]. A human epidemiologic study reported a significant negative impact of $\mathrm{SO}_{2}$ exposure during the second month before conception on fecundability [29]. Based on these reports, although the direct deposition rates of pollutants into the ovary and uterus are not known, it is not plausible to hypothesize that short, acute exposure to ambient air pollution during the IVF treatment cycle would affect the IVF treatment outcome. Additionally, the follicular and luteal phases are very short, continuous periods and analyzing the effect of pollution exposure during each of these phases separately may be irrelevant. It would likely be more informative to focus on the general pattern of IVF outcomes and air pollution levels during longer time periods to generate a hypothesis about the association between these 2 variables. Thus, we analyzed a large database without adjusting for any variables. The ascertainment bias may not be severe, which is commonly assumed in machine learning applications for large-scale data [30].

Our study has several limitations. Although we found similar patterns of IVF outcomes and air pollution levels, the association between these 2 variables should be further investigated by controlling for clinically important confounding factors. Furthermore, as most subjects in this retrospective study resided in a specific area, it is difficult to generalize our findings to a population-level conclusion based on our results. As the purpose of this study was to generate a hypothesis, it is impossible to elucidate any causal inference between air pollution IVF outcomes. Finally, we used the average concentrations of the air pollutants across the 318 sites rather than not the concentrations specific to the patients' residence. However, when we analyzed the concentrations of the air pollutants across the 318 sites, there were no significant differences between sites. Despite these limitations, this is the largest study analyzing data accumulated over 7 years. Moreover, this is the first study to assess the association between within-year variations in IVF success rates and air pollution levels, which generated an important hypothesis to serve as a basis for future studies.

In conclusions, this study, a distinct similarity between within-year variations in IVF failure rates and air pollution was found using a large, long-term database. The IVF success rate was highest in the summer when the PM concentration was lowest. Further studies to examine the mechanisms by which air pollutants affect human reproduction and the association between IVF success and air pollutant exposure are warranted.

\section{Acknowledgements}

This work was supported in part by grants from the National Research Foundation of Korea (NRF-2016R1D$1 \mathrm{~A} 1 \mathrm{~B} 03932068)$ and the Korean Health Industry Development Institute (HI18C1837) funded by the Korean 


\section{Obstetrics \& Gynecology Science}

Vol. 63, No. 1, 2020

government.

\section{Conflict of interest}

No potential conflict of interest relevant to this article was reported.

\section{Ethical approval}

This study was approved by the Institutional Review Board of CHA Medical Center, CHA University, Seoul, Korea (GCI-1840).

\section{Patient consent}

Informed consent was waived because of the retrospective study design.

\section{References}

1. European Environment Agency. Air quality in Europe-2014 report [Internet]. Luxembourg: Publications Office of the European Union; c2014 [cited year month day]. Available from: https://www.eea.europa.eu/publications/air-quality-in-europe-2014.

2. Cosselman KE, Navas-Acien A, Kaufman JD. Environmental factors in cardiovascular disease. Nat Rev Cardiol 2015;12:627-42.

3. Shah AS, Lee KK, McAllister DA, Hunter A, Nair H, Whiteley $W$, et al. Short term exposure to air pollution and stroke: systematic review and meta-analysis. BMJ 2015;350:h1295.

4. Atkinson RW, Kang S, Anderson HR, Mills IC, Walton HA. Epidemiological time series studies of PM2.5 and daily mortality and hospital admissions: a systematic review and meta-analysis. Thorax 2014;69:660-5.

5. Karakis I, Kordysh E, Lahav T, Bolotin A, Glazer Y, Vardi H, et al. Life prevalence of upper respiratory tract diseases and asthma among children residing in rural area near a regional industrial park: cross-sectional study. Rural Remote Health 2009;9:1092.
6. Wu J, Ren C, Delfino RJ, Chung J, Wilhelm M, Ritz B. Association between local traffic-generated air pollution and preeclampsia and preterm delivery in the south coast air basin of California. Environ Health Perspect 2009;117:1773-9.

7. Takeda K, Tsukue N, Yoshida S. Endocrine-disrupting activity of chemicals in diesel exhaust and diesel exhaust particles. Environ Sci 2004;11:33-45.

8. Wang J, Xie P, Kettrup A, Schramm KW. Inhibition of progesterone receptor activity in recombinant yeast by soot from fossil fuel combustion emissions and air particulate materials. Sci Total Environ 2005;349:120-8.

9. Yauk C, Polyzos A, Rowan-Carroll A, Somers CM, Godschalk RW, Van Schooten FJ, et al. Germ-line mutations, DNA damage, and global hypermethylation in mice exposed to particulate air pollution in an urban/industrial location. Proc Natl Acad Sci U S A 2008;105:605-10.

10. Gao H, Ma MQ, Zhou L, Jia RP, Chen XG, Hu ZD. Interaction of DNA with aromatic hydrocarbons fraction in atmospheric particulates of Xigu District of Lanzhou, China. J Environ Sci (China) 2007;19:948-54.

11. Maluf M, Perin PM, Foltran Januário DA, Nascimento Saldiva PH. In vitro fertilization, embryo development, and cell lineage segregation after pre- and/or postnatal exposure of female mice to ambient fine particulate matter. Fertil Steril 2009;92:1725-35.

12. Perin PM, Maluf M, Czeresnia CE, Nicolosi Foltran Januário DA, Nascimento Saldiva PH. Effects of exposure to high levels of particulate air pollution during the follicular phase of the conception cycle on pregnancy outcome in couples undergoing in vitro fertilization and embryo transfer. Fertil Steril 2010;93:301-3.

13. Mohallem SV, de Araújo Lobo DJ, Pesquero CR, Assunção JV, de Andre PA, Saldiva PH, et al. Decreased fertility in mice exposed to environmental air pollution in the city of Sao Paulo. Environ Res 2005;98:196-202.

14. Rocha E Silva IR, Lichtenfels AJ, Amador Pereira LA, Saldiva PH. Effects of ambient levels of air pollution generated by traffic on birth and placental weights in mice. Fertil Steril 2008;90:1921-4.

15. Missmer SA, Pearson KR, Ryan LM, Meeker JD, Cramer DW, Hauser R. Analysis of multiple-cycle data from couples undergoing in vitro fertilization: methodologic issues and statistical approaches. Epidemiology 2011;22:497-504. 


\section{Obstetrics \& Gynecology Science}

Jongkyeong Kang, et al. Pattern of air pollution and IVF result

16. Maity A, Williams PL, Ryan L, Missmer SA, Coull BA, Hauser R. Analysis of in vitro fertilization data with multiple outcomes using discrete time-to-event analysis. Stat Med 2014;33:1738-49.

17. Choe SA, Jun YB, Lee WS, Yoon TK, Kim SY. Association between ambient air pollution and pregnancy rate in women who underwent IVF. Hum Reprod 2018;33:10718.

18. Han EJ, Kim SK, Lee JR, Jee BC, Suh CS, Kim SH. Multiple pregnancy after single or multiple embryo transfer performed according to Korean guidelines. Clin Exp Reprod Med 2015;42:169-74.

19. de Boor C. A practical guide to splines. New York (NY): Springer-Verlag; 1978.

20. Carré J, Gatimel N, Moreau J, Parinaud J, Leandri R. Influence of air quality on the results of in vitro fertilization attempts: a retrospective study. Eur J Obstet Gynecol Reprod Biol 2017;210:116-22.

21. Wood S, Quinn A, Troupe S, Kingsland C, Lewis-Jones I. Seasonal variation in assisted conception cycles and the influence of photoperiodism on outcome in in vitro fertilization cycles. Hum Fertil (Camb) 2006;9:223-9.

22. Stolwijk AM, Reuvers MJ, Hamilton CJ, Jongbloet PH, Hollanders JM, Zielhuis GA. Seasonality in the results of in-vitro fertilization. Hum Reprod 1994;9:2300-5.

23. Kirshenbaum M, Ben-David A, Zilberberg E, Elkan-Miller T, Haas J, Orvieto R. Influence of seasonal variation on in vitro fertilization success. PLoS One 2018;13:e0199210.

24. Tamura H, Nakamura Y, Korkmaz A, Manchester LC, Tan DX, Sugino N, et al. Melatonin and the ovary: physiological and pathophysiological implications. Fertil Steril 2009;92:328-43.

25. Nobles CJ, Schisterman EF, Ha S, Buck Louis GM, Sherman S, Mendola P. Time-varying cycle average and daily variation in ambient air pollution and fecundability. Hum Reprod 2018;33:166-76.

26. Legro RS, Sauer MV, Mottla GL, Richter KS, Li X, Dodson WC, et al. Effect of air quality on assisted human reproduction. Hum Reprod 2010;25:1317-24.

27. Mao L, Hu M, Pan B, Xie Y, Petersen EJ. Biodistribution and toxicity of radio-labeled few layer graphene in mice after intratracheal instillation. Part Fibre Toxicol 2016;13:7.

28. Lee CH, Shim HE, Song L, Moon HG, Lee K, Yang JE, et al. Efficient and stable radiolabeling of polycyclic aromatic hydrocarbon assemblies: in vivo imaging of diesel exhaust particulates in mice. Chem Commun (Camb) 2019;55:447-50.

29. Dejmek J, Jelínek R, Solansky' I, Benes I, Srám RJ. Fecundability and parental exposure to ambient sulfur dioxide. Environ Health Perspect 2000;108:647-54.

30. Murphy KP. Machine learning: a probabilistic perspective. Cambridge (MA): MIT press; 2012. 